\title{
Regresi Linier Berganda Untuk Menganalisis Pendapatan Petani Pala
}

\author{
${ }^{1}$ Jamner R. Lawendatu, ${ }^{2}$ John S. Kekenusa, ${ }^{3}$ Djoni Hatidja \\ ${ }^{1}$ Program Studi Matematika, FMIPA, UNSRAT, jrlawendatu@yahoo.com \\ ${ }^{2}$ Program Studi Matematika, FMIPA, UNSRAT, johnkekenusa@yahoo.com \\ ${ }^{3}$ Program Studi Matematika, FMIPA, UNSRAT, dhatidja@yahoo.com
}

\begin{abstract}
Regency of Sangihe Islands is a region that has potential in the field of horticulture, especially when producing nutmeg crop that originally from Indonesia as a trading commodity. The purpose of this study is to find out how much is the chosen variable affect the farmer income in Sensong village by using multiple regression analysis. This study used primary and secondary data, with a "simple random sampling" as a sampling technique. Based on this research, the variables that have the influence on the farmer's income is the amount of nutmeg production and labor costs. The resulting coefficient of determination is 0.930 , or 93 percent.
\end{abstract}

Keywords : Multiple regression analysis, the nutmeg farmers income

\begin{abstract}
Abstrak
Kabupaten Kepulauan Sangihe adalah daerah yang cukup berpotensi dalam bidang perkebunan terutama dalam menghasilkan tanaman pala yang merupakan salah satu tanaman asli Indonesia sebagai ko moditas perdagangan di dalam dan luar negeri. Tujuan penelitian ini adalah untuk mengetahui seberapa besar pengaruh variabel yang telah dipilih terhadap pendapatan petani pala di Desa Sensong dengan menggunakan analisis regresi berganda. Dalam penelitian ini digunakan data primer dan sekunder, dengan simple random sampling sebagai teknik pengambilan sampel. Berdasarkan hasil penelitian, variabel yang memiliki pengaruh terhadap pendapatan petani pala adalah ju mlah produksi biji pala dan biaya tenaga kerja. Nilai koefisien determinasi yang dihasilkan adalah 0,930 atau 93 persen.
\end{abstract}

Kata kunci : Analisis regresi berganda, pendapatan petani pala

\section{Pendahuluan}

Pembangunan pertanian bertujuan untuk meningkatkan hasil dan mutu produksi, meningkatkan pendapatan dan taraf hidup masyarakat, memperluas lapangan kerja dan kesempatan berusaha, menunjang pembangunan industri serta meningkatkan ekspor sekaligus mengurangi import hasil pertanian.

Untuk meningkatkan produksi pertanian khususnya sektor perkebunan yang terus menerus, hanya dapat dicapai melalui pertanian tangguh. Konsep pertanian tangguh ialah pertanian yang dinamis dan ulet mampu secara optimal memanfaatkan sumber daya alam, tenaga dan teknologi yang ada pada lingkungan fisik dan sosial tempatnya, sekaligus mampu meningkatkan kesejahteraan petani.

Kabupaten Kepulauan Sangihe sebagai bagian yang tidak terpisahkan dari provinsi Sulawesi Utara, merupakan salah satu daerah yang cukup potensial dalam bidang perkebunan dan mayoritas penduduk dalam memenuhi kebutuhannya sehari-hari didapat dari hasil perkebunan selain hasil laut, tanaman pangan dan hortikultura

\subsection{Deskripsi Tanaman Pala}

Tanaman pala termasuk tanaman tahunan yang pada mulanya terdapat dihutan-hutan tropika, tumbuh tegak dan mempunyai mahkota yang rindang. Secara keseluruhan, tajuk pohon bentuknya bulat atau bulat mendatar sampai silendris. Daun pala berwarna hijau sampai hijau tua mengkilap.Buah pala bentuknya bulat atau bulat panjang sampai lonjong. Ukuran buah pala bervariasi dari kecil sampai besar , berwarna hijau kekuning-kuningan. Fuli atau serat tipis terdapat 
antara daging dan biji buah pala. Fuli ini berwarna merah atau kuning muda dapat diambil minyaknya.Biji pala bentuknya variasi, dari lonjong sampai bulat [4].

\subsection{Regresi Linier Berganda}

Analisis yang memiliki variabel bebas lebih dari satu disebut analisis regresi berganda. Analisis regresi linier berganda memberikan kemudahan bagi pengguna untuk memasukkan lebih dari satu variabel bebas hingga $k$ dimana banyaknya $k$ kurang dari jumlah observasi (n). Sehingga model regresi linier berganda untuk populasi dapat ditunjukkan sebagai berikut [6]:

$$
Y=\beta_{0}+\beta_{1} X_{1}+\beta_{2} X_{2}+\ldots \ldots+\beta_{k} X_{k}+e
$$

Model regresi linier berganda untuk populasi di atas dapat ditaksir berdasarkan sebuah sampel acak yang berukuran $\mathrm{k}$ dengan model regresi linier berganda untuk sampel, yaitu :

$$
\hat{Y}=b_{0}+b_{1} X_{1}+b_{2} X_{2}+\ldots \ldots+b_{k} X_{k}
$$

\subsection{Uji Asumsi Klasik}

\subsubsection{Uji He te roske das tisitas}

Uji heteroskedastisitas dilakukan untuk menguji apakah dalam sebuah model regresi terjadi ketidaksamaan varians residual dari satu pengamatan ke pengamatan yang lain tetap, maka disebut Heteroskedastisitas [5]. Ada dua cara untuk mengetahui ada tidaknya gejala Heteroskedatisitas yaitu dengan metode garafik dan metode statistik.

Pada metode garfik, jika titik-titik menyebar diatas dan dibawah angka 0 pada sumbu Y tanpa membentuk pola tertentu, maka tidak terjadi heteroskedastisitas. Sedangkan pada metode statistik, dapat dilakukan dengan uji Glesjer. Uji Glejser dilakukan dengan cara meregresikan antara variabel bebas dengan nilai absolut residualnya. Jika nilai signifikansi antara variabel bebas dengan absolut residual lebih dari 0,05 maka tidak terjadi masalah heteroskedastisitas [2].

\subsubsection{Uji Normalitas}

Tujuan uji normalitas adalah untuk menguji apakah dalam sebuah model regresi, variabel terikat dan variabel bebas atau keduanya mempunyai distribusi normal ataukah tidak. Model regresi yang baik adalah distribusi data normal atau mendekati normal. Deteksi normalitas dilakukan dengan melihat grafik Normal Probability Plot [1].

Untuk menguji apakah distribusi data normal atau tidak, dapat dilakukan dengan metode grafik normal probability plot yang membandingkan distribusi kumulatif dari data sesungguhnya dengan distribusi kumulatif dari distribusi normal. Jika data menyebar di sekitar garis dan mengikuti arah garis diagonal maka model regresi memenuhi asumsi normalitas.

Dalam metode statistik dapat menggunakan uji metode statistik One Sample Kolmogorov Smirnov. Uji One Sample Kolomogorov Smirnov digunakan untuk mengetahui distribusi data, apakah mengikuti distribusi normal, poisson, uniform, atau exponential. Dalam hal ini untuk mengetahui apakah distribusi residual terdistribus i normal atau tidak. Residual berdistribusi normal jika nilai signifikansi lebih dari 0,05 [3].

\section{Metodologi Penelitian}

Metode yang digunakan dalam penelitian ini adalah metode studi kasus dengan menggunakan data primer dan data sekunder. Data primer diperoleh dari hasil wawancara langsung dengan responden petani pala, sedangkan data sekunder diambil dari instansi-instansi terkait.

Data yang diperoleh dianalisis dengan menggunakan Analisis Regresi Linier Berganda, dengan persamaan :

$$
Y_{i}=\beta_{0}+\beta_{1} X_{1 i}+\beta_{2} X_{2 i}+\beta_{3} X_{3 i}+\beta_{4} X_{4 i}+\beta_{5} X_{5 i}+\beta_{6} X_{6 i}+\varepsilon_{i}
$$


Dimana : $\quad \mathrm{Y}=$ Pendapatan Petani

$\mathrm{X}_{1}=$ Jumlah anggota keluarga

$\mathrm{X}_{2}=$ Luas Lahan

$\mathrm{X}_{3}=$ Jumlah pohon Pala

$\mathrm{X}_{4}=$ Jumlah produksi Biji Pala

$\mathrm{X}_{5}=$ Biaya Tenaga Kerja

$\mathrm{X}_{6}=$ Biaya produksi

\section{Hasil dan Pembahasan}

\subsection{Uji Asumsi Klasik}

\subsubsection{Uji He te roske das tisitas}

Hasil uji heteroskedastisitas dengan metode garafik dari program SPSS dapat dilihat pada gambar 1 berikut ini:

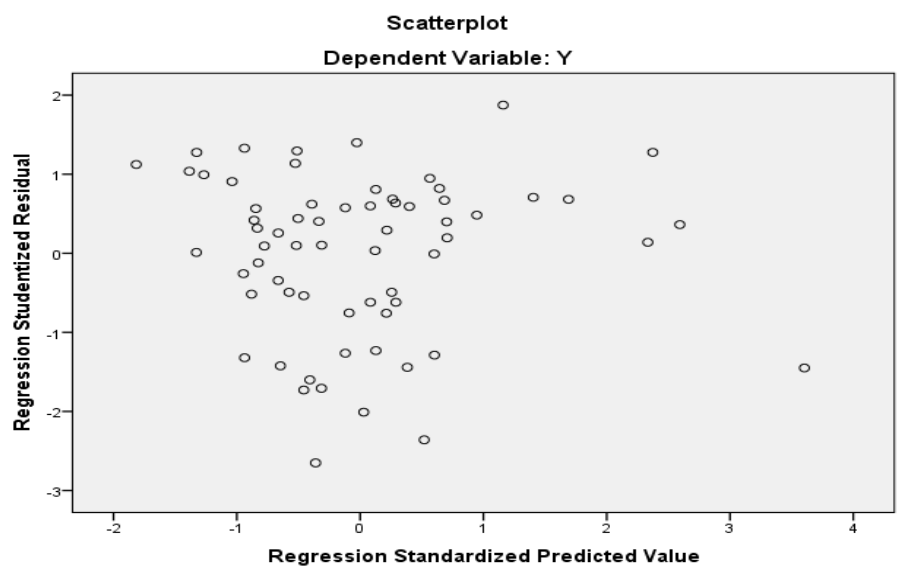

Gambar 1. Hasil Uji Heteroskedastisitas

Hasil pengujian heteroskedastisitas menunjukkan bahwa titik-titik tidak membentuk pola tertentu atau tidak ada pola yang je las serta titik-titik menyebar di atas dan dibawah angka 0 (nol) pada sumbu Y, maka tidak terjadi heteroskedastisitas.

Pengujian heterokedastisitas dapat dilihat juga melalui uji statistik dengan menggunakan uji glesjer, hasil uji ada pada tabel 1 :

Tabel 1. Hasil Uji Glesjer

Coefficients $^{\mathrm{a}}$

\begin{tabular}{|c|c|c|c|c|c|c|}
\hline & \multirow[t]{2}{*}{ Model } & \multicolumn{2}{|c|}{ Unstandardized Coefficients } & \multirow{2}{*}{$\begin{array}{c}\text { Standardized } \\
\text { Coefficients } \\
\text { Beta } \\
\end{array}$} & \multirow[t]{2}{*}{$\mathrm{t}$} & \multirow{2}{*}{ Sig. } \\
\hline & & $\mathrm{B}$ & Std. Error & & & \\
\hline \multirow{7}{*}{1} & (Cons) & 212764.945 & 120732.105 & & 1.762 & .083 \\
\hline & $\mathrm{X} 1$ & $5335.45 d$ & 29726.673 & .030 & .179 & .858 \\
\hline & $\mathrm{X} 2$ & 28.685 & 18.783 & .768 & 1.527 & .132 \\
\hline & $\mathrm{X} 3$ & -2281.523 & 2234.921 & -.627 & -1.021 & .312 \\
\hline & $\mathrm{X} 4$ & -795.509 & 5913.418 & -.080 & -.135 & .893 \\
\hline & $\times 5$ & -.072 & .223 & -.079 & -.324 & .747 \\
\hline & X6 & -.117 & .887 & -.049 & -.132 & .895 \\
\hline
\end{tabular}

a. Depend ent Variable: AbsUi 
Dari tabel 1, dapat diketahui bahwa nilai signifikansi keenam variabel independen lebih dari 0,05. Dengan demikian dapat disimpulkan bahwa tidak terjadi masalah heteroskedastisitas pada model regresi tersebut

\subsubsection{Uji Normalitas}

Hasil uji normalitas dengan metode grafik dapat dilihat pada gambar 2 berikut ini:

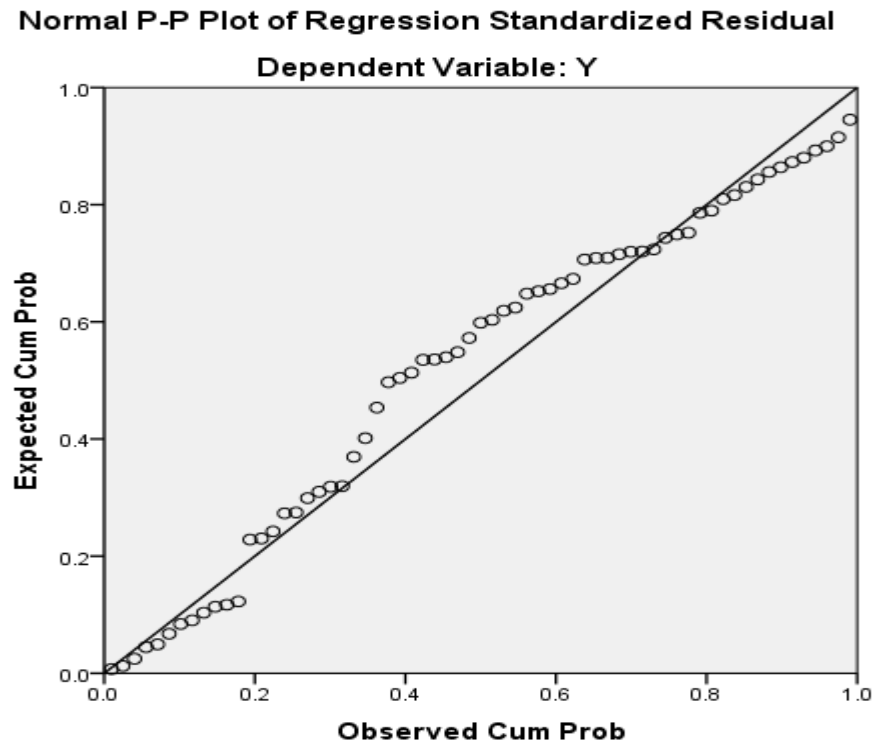

Gambar 2. Hasil Uji Normalitas

Pada gambar 2 dapat dilihat bahwa grafik normal probability plot menunjukkan pola grafik yang normal. Hal ini terlihat dari titik yang menyebar di sekitar grafik normal dan penyebarannya mengikuti garis diagonal.

Hasil uji normalitas dengan metode statistik dapat dilihat pada tabel 2 uji One Sample Kolomogorov Smirnov.

Tabel 2. Hasil Uji One Sample Kolomogorov Smirnov

\begin{tabular}{|c|c|c|}
\hline & & $\begin{array}{l}\text { Unstandardized } \\
\text { Residual }\end{array}$ \\
\hline $\mathrm{N}$ & & 65 \\
\hline \multirow{3}{*}{ Normal Parameters ${ }^{a, b}$} & Mean & $0 \mathrm{E}-7$ \\
\hline & Std. Deviation & 243674.92046530 \\
\hline & Absolute & .127 \\
\hline \multirow[t]{2}{*}{ Most Extreme Differences } & Positive & .074 \\
\hline & Negative & -.127 \\
\hline Kolmogorov-Smirnov Z & & 1.028 \\
\hline Asymp. Sig. (2-tailed) & & .241 \\
\hline
\end{tabular}

a. Test distribution is Normal.

b. Calculated from data.

Dari output di atas dapat diketahui bahwa nilai signifikansi (Asymp.Sig 2-tailed) sebesar 0,241. Karena signifikansi lebih dari $0,05(0,241>0,05)$, maka nilai residual tersebut telah normal. Oleh karena ini dapat disimpulkan bahwa model regresi layak dipakai karena memenuhi asumsi normalitas. 


\subsection{Uji Koefisien Regresi Linier Berganda}

\subsubsection{Uji Simultan (Uji F)}

Uji-F digunakan untuk menguji koefisien regresi secara bersama-sama. Hasil uji f pada penelitian ini dapat dilihat pada tabel 3 berikut ini:

Tabel 3. Hasil Uji F

ANOVA $^{a}$

\begin{tabular}{|c|c|c|c|c|c|}
\hline Model & Sum of Squares & $\mathrm{df}$ & Mean Square & $\mathrm{F}$ & Sig. \\
\hline Regression & $\begin{array}{c}\text { 39057399876695.68 } \\
\text { Residual }\end{array}$ & \multicolumn{1}{c|}{6} & 6509566646115.946 & 102.150 & $.000^{\mathrm{b}}$ \\
& 2294111751211.315 & 36 & 63725326422.537 & & \\
Total & $\begin{array}{l}41351511627906.99 \\
0\end{array}$ & 42 & & & \\
\hline
\end{tabular}

a. Dependent Variable: $Y$

b. Predictors: (Constant), X6, X1, X2, X5, X3, X4

Dari hasil uji F pada penelitian ini didapatkan nilai $F$ hitung sebesar 102,150 dengan angka signifikansi sebesar 0,000. Dengan tingkat signifikansi 95\% $(\alpha=0,05)$. Angka signifikansi sebesar $0,000<0,05$. Atas dasar perbandingan tersebut, maka Ho ditolak atau berarti variabel jumlah anggota keluarga (X1), luas lahan (X2), jumlah pohon pala (X3), jumlah produksi biji pala (X4), biaya tenaga kerja (X5) dan biaya produksi (X6) mempunyai pengaruh yang signifikan secara bersama-sama terhadap pendapatan petani pala.

\subsubsection{Uji t}

Uji- $t$ digunakan untuk menguji koefisien regresi berganda secara parsial (individu). Hasil uji t pada penelitian ini dapat dilihat pada tabel 4 berikut ini:

Tabel 4. Hasil Uji t

\begin{tabular}{|c|c|c|c|c|c|c|c|}
\hline \multicolumn{8}{|c|}{ Coefficients $^{\mathrm{a}}$} \\
\hline \multirow{2}{*}{ Model } & \multicolumn{2}{|c|}{ Unstandardized Coefficients } & \multirow{2}{*}{$\begin{array}{c}\begin{array}{c}\text { Standardized } \\
\text { Coefficients }\end{array} \\
\text { Beta }\end{array}$} & \multirow{2}{*}{$\mathrm{t}$} & \multirow{2}{*}{ Sig. } & \multicolumn{2}{|c|}{ Collinearity Statistics } \\
\hline & B & Std. Error & & & & Tolerance & VIF \\
\hline (Cons) & -274315.626 & 215524.306 & & -1.273 & .208 & & \\
\hline $\mathrm{X} 1$ & 80355.432 & 53066.419 & .064 & 1.514 & .135 & .581 & 1.722 \\
\hline $\mathrm{X} 2$ & 17.194 & 33.531 & .065 & .513 & .610 & .065 & 15.489 \\
\hline X3 & 1585.562 & 3989.658 & .062 & .397 & .693 & .043 & 23.105 \\
\hline $\mathrm{X} 4$ & 77751.648 & 10556.307 & 1.101 & 7.365 & .000 & .047 & 21.503 \\
\hline$\times 5$ & -1.150 & .397 & -.179 & -2.894 & .005 & .271 & 3.695 \\
\hline$x 6$ & -2.522 & 1.584 & -.149 & -1.592 & .117 & .119 & 8.429 \\
\hline
\end{tabular}

a. Dependent Variable: $Y$

Berdasarkan tabel, maka hasil uji t dapat dijelaskan bahwa yang memiliki pengaruh terhadap pendapatan petani pala adalah jumlah produksi biji pala (X4) dengan nilai siginifikan sebesar 0,000 dan biaya tenaga kerja (X5) dengan nilai signifikan sebesar 0,005. Sedangkan variabel jumlah anggota keluarga (X1), luas lahan (X2), jumlah pohon pala (X3) dan biaya produksi (X6) tidak memiliki pengaruh yang signifikan terhadap pendapatan petani pala karena nilai signifikasi lebih dari 0,05 . 


\subsubsection{Koefis ien Determinasi}

Nilai koefisien determinasi $\left(\mathrm{R}^{2}\right)$ ini mencerminkan seberapa besar variasi dari variabel terikat $\mathrm{Y}$ dapat diterangkan oleh variabel bebas $\mathrm{X}$, atau dengan kata lain seberapa besar $\mathrm{X}$ memberikan kontribusi terhadap Y. Nilai Adjusted $\mathrm{R}^{2}$ dapat dilihat pada tabel 5 berikut ini:

Tabel 5. Hasil Uji Regresi (Koefisien Determinasi)

\begin{tabular}{|l|l|r|r|c|}
\hline Model & M & R Square & $\begin{array}{c}\text { Adjusted R } \\
\text { Square }\end{array}$ & $\begin{array}{c}\text { Std. Error of the } \\
\text { Estimate }\end{array}$ \\
\hline 1 & $.969^{\mathrm{a}}$ & .940 & .933 & 255968.677 \\
\hline
\end{tabular}

a. Predictors: (Constant), X6, X1, X5, X2, X4, X3

b. Dependent Variable: $Y$

Pada tabel 5 dapat dilihat bahwa nilai Adjusted $\mathrm{R}^{2}$ adalah sebesar 0,933. Hal ini dapat diartikan bahwa sebesar 93,3\% keragaman dari pendapatan petani pala dapat dijelaskan oleh jumlah anggota keluarga (X1), luas lahan (X2), jumlah pohon pala (X3), jumlah produksi biji pala (X4), biaya tenaga kerja (X5) dan biaya produksi (X6), sedangkan sisanya diterangkan oleh faktor lain yang tidak dite liti.

\subsubsection{Analis is Regresi Linier Berganda}

Dari hasil regresi dengan menggunakan program SPSS, maka didapatkan koefisien regresi yang dapat dilihat pada tabel 6 berikut ini :

Tabel 6. Hasil Uji Regresi (Koefisien Regresi)

\begin{tabular}{|c|c|c|c|c|c|c|}
\hline \multicolumn{7}{|c|}{ Coefficients $^{\mathrm{a}}$} \\
\hline \multirow{2}{*}{\multicolumn{2}{|c|}{ Model }} & \multicolumn{2}{|c|}{ Unstandardized Coefficients } & \multirow{2}{*}{$\begin{array}{c}\begin{array}{c}\text { Standardized } \\
\text { Coefficients }\end{array} \\
\text { Beta }\end{array}$} & \multirow[t]{2}{*}{$\mathrm{t}$} & \multirow[t]{2}{*}{ Sig. } \\
\hline & & B & Std. Error & & & \\
\hline \multirow{3}{*}{1} & (Constant) & -94466.090 & 153764.195 & & -.614 & .541 \\
\hline & $x 4$ & 79593.560 & 3437.512 & 1.127 & 23.154 & .000 \\
\hline & $\times 5$ & -1.539 & .312 & -.240 & -4.932 & .000 \\
\hline
\end{tabular}

a. Dependent Variable: $Y$

Berdasarkan pada tabel 6 maka didapatkan persamaan regresi linier berganda sebagai berikut:

$$
Y=-94466,09+79593,56 \times 4-1,539 \times 5
$$

Persamaan di atas dapat dijelaskan sebagai berikut :

1. Nilai 79593,56 pada variabel X4 adalah bernilai positif sehingga dapat dikatakan bahwa semakin tinggi tingkat jumlah pruduksi biji pala (X4), maka akan semakin tinggi pula pendapatan petani pala.

2. Nilai $-1,539$ pada variabel $X 5$ adalah bernilai negatif sehingga dapat dikatakan bahwa semakin rendah tingkat biaya tenaga kerja, maka akan semakin tinggi pula pendapatan petani pala.

Sedangkan koefisien determinasi dari persamaan diatas dapat dilihat pada table berikut ini :

Table 7. Uji Koefisien Determinasi

\begin{tabular}{|c|r|r|r|c|}
\hline Model & $\mathrm{R}$ & $\begin{array}{c}\mathrm{R} \\
\text { Square }\end{array}$ & $\begin{array}{c}\text { Adjusted } \mathrm{R} \\
\text { Square }\end{array}$ & $\begin{array}{c}\text { Std. Error of the } \\
\text { Estimate }\end{array}$ \\
\hline 1 & $.965^{\mathrm{a}}$ & .932 & .930 & 263049.475 \\
\hline
\end{tabular}

a. Predictors: (Constant), X5, X4

b. Depend ent Variable: $Y$ 
Dapat dikatakan bahwa 93\% keragaman dari pendapatan petani pala dapat dijelaskan oleh $\mathrm{Y}=-94466,09+79593,56 \mathrm{X} 4-1,539 \mathrm{X} 5$.

\section{Kesimpulan}

Pengujian hipotesis dengan menggunakan uji $\mathrm{F}$ dapat dije laskan bahwa keenam variable yaitu variabel jumlah anggota keluarga (X1), luas lahan (X2), jumlah pohon pala (X3), jumlah produksi biji pala (X4), biaya tenaga kerja (X5) dan biaya produksi (X6) secara bersama-sama berpengaruh terhadap pendapatan petani pala dengan nilai $F$ hitung sebesar 102,150 dengan angka signifikansi sebesar 0,000. Nilai koefisien determinasi $\left(\mathrm{R}^{2}\right)$ yang dihasilkan adalah 0,930 atau 93\% .

Pada uji regresi linier berganda diperoleh persamaan sebagai berikut :

$$
Y=\mathbf{- 9 4 4 6 6 , 0 9 + 7 9 5 9 3 , 5 6 ~ X 4 ~ - ~ 1 , 5 3 9 ~ X 5 ~}
$$

Berdasarkan persamaan diatas, dilihat bahwa yang memiliki pengaruh terhadap pendapatan petani pala adalah jumlah produksi biji pala (X4) dengan nilai koef is ien regresi sebesar 79593,56 dan biaya tenaga kerja dengan nilai koefisien regresi sebesar 1,539. Nilai koefisien determinasi yang dihasilkan adalah 0,930 atau $93 \%$.

\section{Daftar Pustaka}

[1] Ghozali, I, 2005, Aplikasi Analisis Multivariat dengan program SPSS, BadanPenerbit Universitas Diponegoro, Semarang

[2] Janie, D. N. A. 2012. Statistik Deskriptif dan Regresi Linier Berganda dengan SPSS. Universitas Semarang. Semarang

[3] Priyatno, D. 2013. Analis is Korelasi, Regresi dan Multivariate dengan SPSS. Gava Media, Yogyakarta

[4] Rukmana, R. 2006. Us aha Tani Pala. CV. Aneka Ilmu. Semarang. 182/71.02/009/2007

[5] Santoso, S. 2000. Latihan SPSS Statistik Parmetik.Gramedia, Jakarta.

[6] Supranto, J. 2004. Analisis Multivariat Arti dan Interpretasi. Rineka Cipta. Jakarta 